\title{
Gastric Type Adenocarcinoma with Fundic Gland Differentiation in the Duodenum Resected by ESD (Endoscopic Submucosal Dissection)
}

\author{
Orita $\mathrm{H}^{* 1}$, Ito $\mathrm{T}^{1}$, Kushida $\mathrm{T}^{1}$, Sakurada $\mathrm{M}^{1}$, Maekawa $\mathrm{H}^{1}$, Yamano $\mathrm{M}^{2}$, Wada $\mathrm{R}^{2}$, Yao $\mathrm{T}^{3}$ and Sato $\mathrm{K}^{1}$ \\ ${ }^{1}$ Department of Surgery, Juntendo Shizuoka Hospital, Shizuoka, Japan \\ ${ }^{2}$ Department of Pathology, Juntendo Shizuoka Hospital, Shizuoka, Japan \\ ${ }^{3}$ Department of Pathology, Juntendo University School of Medicine, Tokyo, Japan
}

${ }^{*}$ Corresponding author: Orita H, MD, PhD, Department of Surgery, Juntendo Shizuoka Hospital, Shizuoka, Japan, Fax: 055-946-0514, Tel: 055-948-3111,E-mail: oriori@juntendo.ac.jp

Citation: Orita H, Ito T, Kushida T, Sakurada M, Maekawa H, et al. (2014) Gastric Type Adenocarcinoma with Fundic Gland Differentiation in the Duodenum Resected by ESD (Endoscopic Submucosal Dissection). J Cancer Sci Clin Oncol 1(1): 101. doi: 10.15744/2394-6520.1.101

Received Date: March 14, 2014 Accepted Date: November 26, 2014 Published Date: December 03, 2014

\begin{abstract}
Background: Gastric type adenocarcinoma with fundic gland differentiation (GA-FG) has been reported as a new, rare, chief cell differentiation composed carcinoma. Clinicopathologically, it exists on the gastric cardia/fundus, with low proliferative activity and low-grade malignancy. Until now, there has been no report of this GA-FG type cancer in the duodenum.

Case presentation: In this case, we report a case that coincidentally diagnosed GA-FG neighboring to Brunner's glands hyperplasia in the duodenum, and successfully resected by ESD (Endoscopic Submucosal Dissection). Unfortunately, owing to a thin submucosal, pin hole perforation was caused while snaring the tumor. Endoscopic 4 clippings, expelled remaining abdominal air, and 2 weeks non oral in take was cured acute peritonitis.

Conclusions: We report the experience of the rare case of Gastric type adenocarcinoma with fundic gland differentiation in the duodenum, arising from Brunner's gland hamartoma / hyperplasia, resected by ESD (Endoscopic Submucosal Dissection).

Keywords: Duodenal neoplasms; Fundic gland; Chief cells; Gastric; Cell differentiation; ESD
\end{abstract}

\section{Introduction}

Ueyama $\mathrm{H}$ and Yao T etc.[1] proposed gastric adenocarcinoma of fundic gland type (GA-FG) as a new entity within gastric adenocarcinomas. They reported 12 cases and described their clinicopathologic features. Histologically, they were well differentiated adenocarcinomas composed of chief cells. Clinicopathologically, some authors have reported these on the gastric cardia/fundus, with low proliferative activity and low-grade malignancy [2-4].

Previously, some strange cases on the gastric cardia, such as parietal cell carcinoma have been reported [5,6]. Differentiation of parietal cells was confirmed by staining for $\mathrm{H}+/ \mathrm{K}+$ ATPase in one case [7]. Until now, there has been no report of this GA-FG type cancer in the duodenum. Meanwhile, duodenal neoplasm is very rare, accounting for $0.4 \%$ of gastro-intestinal malignancies [8,9].

In this case, we report the first case of a duodenal variant of adenocarcinoma of fundic gland type arising from a Brunner's gland hamartoma/hyperplasia and successfully resected by ESD (Endoscopic Submucosal Dissection).

\section{Case presentation}

A 67-year-old male was routinely seen at a hospital after a rectal cancer operation in December 2005. Every year he received a GI fiber examination. Five years after the operation, gastric endoscopic examination revealed a small nodular lesion at the bulbus, and subsequently a mucosal biopsy was performed (Figure 1a).

Microscopically, the biopsy specimen demonstrated characteristics of gastric adenocarcinoma of fundic gland type. Laboratory examinations revealed that all parameters were within normal limits. CT scan showed no duodenal wall invasion to pancreas and no lymph node metastases.

We firstly planned to resect the tumor with endoscopic mucosal resection with a cap-fitted endoscope (EMR-C). Nevertheless a large amount of $0.4 \%$ sodium hyaluronate solution was injected into the submucosal layer because mucosal lesions could not be adequately lifted. 
Therefore, we performed EMR using endoscopic submucosal dissection (ESD) technique to remove the tumor completely [with] one segment resection. ESD achieved complete resection of the tumor, which was $2.5 \mathrm{~cm}$ in diameter (Figure1b).

Unfortunately, owing to a thin submucosa, a pinhole perforation developed as a complication of snaring of the tumor, with peritonitis ensuing. Four endoscopic clippings were performed, and the remaining abdominal air was expelled with a 20 gauge needle (Figure 1c). A small amount of free air was detected by abdominal X-ray after ESD. After two weeks of observation with non-oral intake, the acute peritonitis resolved, a gastrografin exam showed no duodenal wall fistula, so we started oral intake. The patient was discharged 18 days after surgery. The resected specimen was fixed and the tumor was diagnosed by histopathological examination as gastric type adenocarcinoma with fundic gland differentiation.

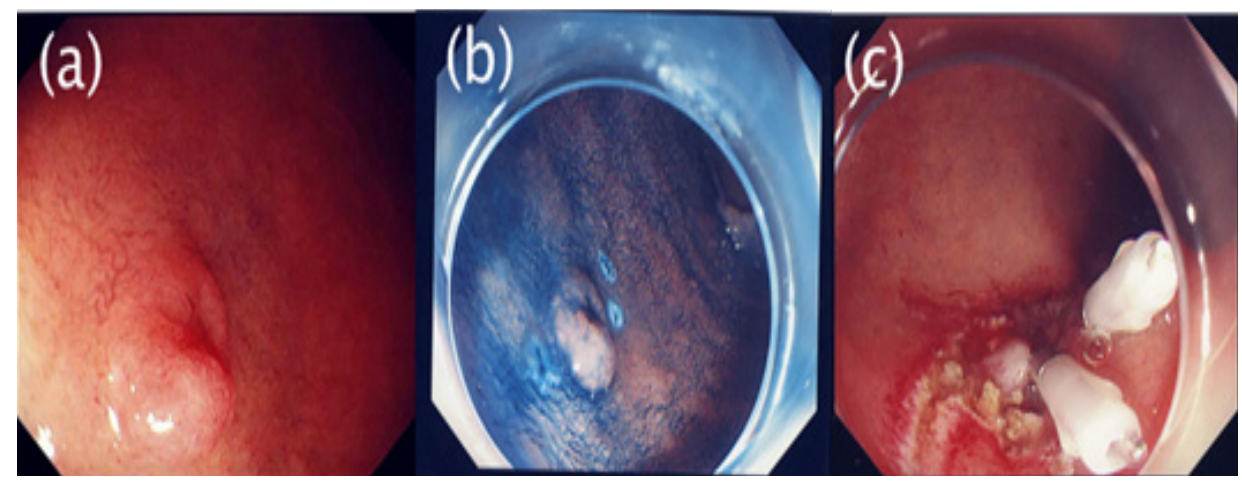

Figure 1: (a) Endoscopic findings of the bulbus revealed small elevated tumor about $10 \mathrm{~mm}$ in size

(b) ESD achieved complete resection of the tumor with $2.5 \mathrm{~cm}$ diameter

(c) Four endoscopic clippings were performed and cured pin hole perforation

Pathological report: The resected tumor specimen measured 5 x $5 \mathrm{~mm}$ in size. Histopathologically, the lesion was composed of two elements: Gastric type adenocarcinoma with fundic gland differentiation, and an excess of Brunner's glands (Figure 2a,b). Due to this feature, this carcinoma was thought to arise from Brunner's gland hamartoma / hyperplasia.

The carcinoma cells were characterized by pale gray-blue, basophilic cytoplasm and enlarged round nuclei with occasional small nucleoli, mimicking chief cells (Figure 2c). Immunohistochemically, carcinoma cells revealed diffuse positivity for MUC6 (Figure 3e) and pepsinogen-I (Figure 3f), and were weakly positive for MUC5AC (Figure 3d), minimally positive for H+/K+ -ATPase (Figure 3g), and negative for MUC2 (Figure 3c). There were a few Ki-67 positive cells (1 2\%) (Figure 3h). The tumor cells were negative for CD10, p53 and Chromogranin A. The result was compatible with that of gastric adenocarcinoma with chief cell differentiation. No lymphovascular invasion was recognized. The lateral and vertical margins were histologically negative.
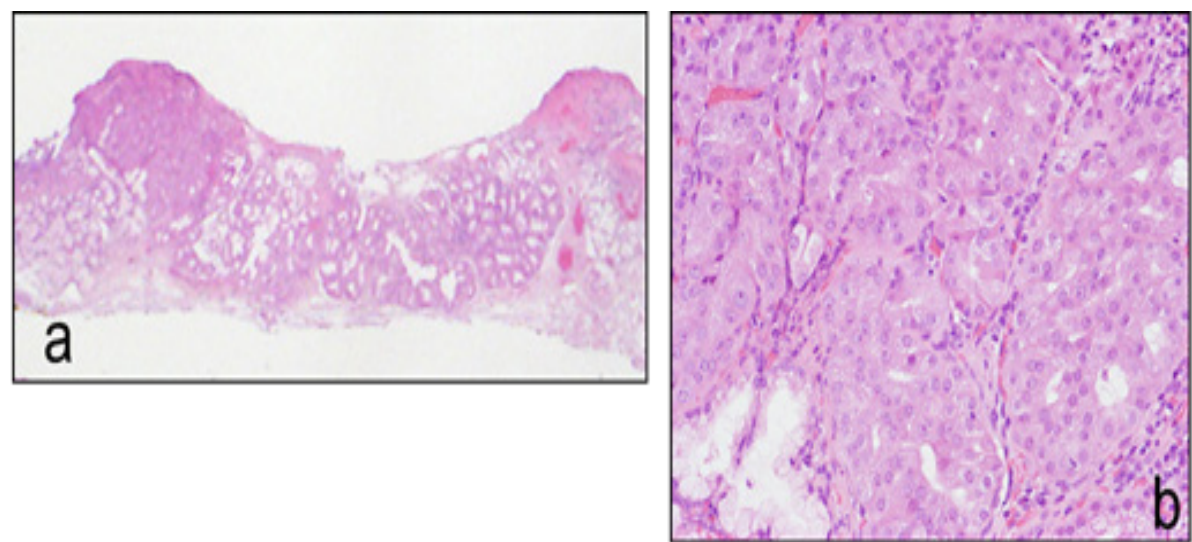

Figure 2: Histological examination of the EMR specimen of this case (hematoxylin and eosin stain)

Figure 2: a) In low-power view. The well-demarcated lesion is composed of adenocarcinoma and an excess of Brunner's glands (HE, $\mathrm{x}$ 40) b) In high power view, the adenocarcinoma shows irregular tubular structure without cell polarity, composed of highly differentiated round columnar cell mimicking chief cell. The carcinoma cells have pale gray-blue, basophilic cytoplasm and enlarged nuclei with small nucleoli (HE, x 200) 


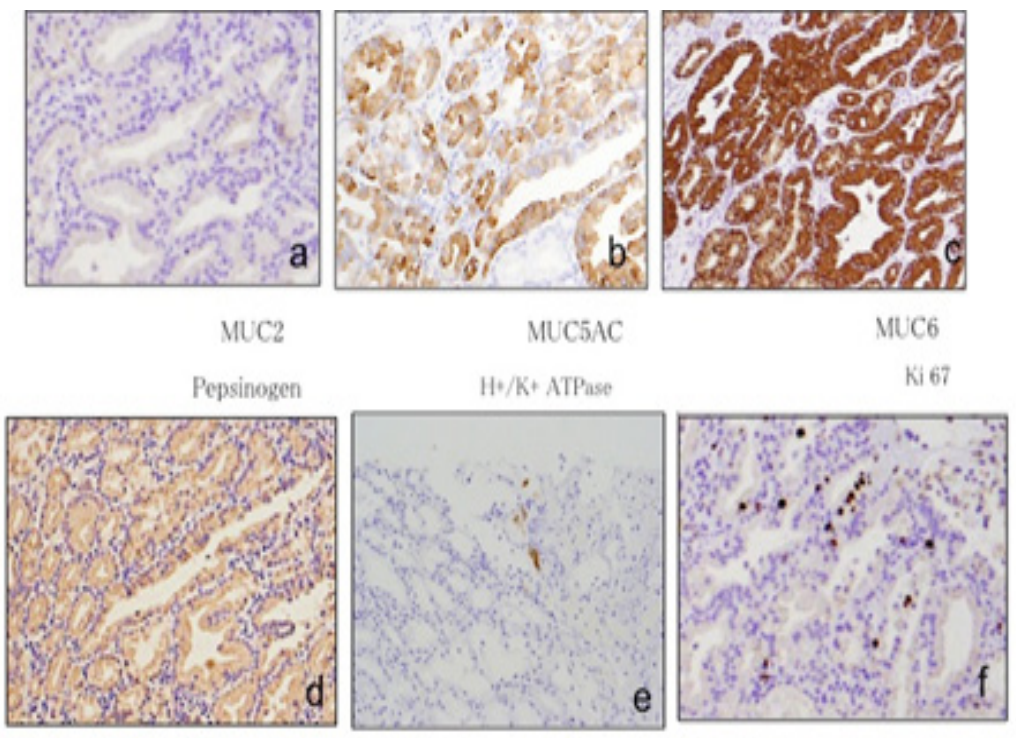

Figure 3: Immunohistochemical examination:

Figure 3: (a-f) : The carcinoma revealed diffuse positivity for MUC6 (c) and pepsinogen-I (d), was focally and weakly positive for MUC5AC (b), minimally positive for $\mathrm{H}+/ \mathrm{K}+$-ATPase (e), and negative for MUC2 (a). There were a few Ki-67 positive cells (1 2\%) (f).

\section{Discussion}

The present duodenal tumor reveals adenocarcinoma possessed Gastric type adenocarcinoma with fundic gland differentiation (GA-FG). Very recently, gastric adenocarcinoma of fundic gland type was proposed. [1-3,10,11]. Histologically, they were well differentiated adenocarcinomas composed of pale gray-blue, basophilic columnar cells with mild nuclear atypia, mimicking chief cells.

Immunohistochemically, scattered positivity for $\mathrm{H}+/ \mathrm{K}+$-ATPase was observed in addition to expression of pepsinogen-I and MUC6, indicating focal differentiation toward parietal cells. Gastric adenocarcinoma of fundic gland type might be classified into 3 categories: chief cell predominant type, parietal cell predominant type, and mixed type [1].

Upon analyzing 10 cases of gastric adenocarcinoma of fundic gland type, all of the 10 cases of fundic gland type gastric adenocarcinoma were chief cell predominant type. But almost all lesions were found to be composed of a mixture of various mildly atypical columnar cells, which resembles histologically to mimic chief cells, parietal cells with eosinophilic cytoplasm, and pyloric glands with clear pale cytoplasm. They also demonstrated mucin phenotypes of fundic gland type gastric adenocarcinoma: MUC 6: 100\%, MUC5AC: 10\%, MUC2: 0\%, CD10 : \%0, CGA 0\%, including only one case of MUC5AC positive.

In contrast, adenocarcinoma of the duodenum is an exceedingly rare condition representing not more than $0.3 \%$ to $0.4 \%$ of all gastrointestinal tract cancers [12]. About $45 \%$ of all carcinomas of the duodenum arise in the third and fourth portions, a distribution pattern that parallels the relative lengths of each portion of this organ [13].

Endoscopic treatments of duodenal tumors are challenging in the presence of the thin duodenal wall and rich vascularity. However, endoscopic resections contribute considerable advantages in terms of organ preservation, risks, recovery and length of hospital stay [14-17].

This case is extremely rare. Although this Brunner's gland hamartoma / hyperplasia in the bulbus has been seen before, no malignant findings have been reported. It seems that a second malignant lesion could be successfully removed without an operation. It is expected that a second operation will be much more difficult than the first operation. Within this line of thinking, it is necessary for a patient to receive routine GI checks postoperatively.

Secondly, this tumor was successfully resected by endoscopic technique, though a pinhole perforation accidently occurred. Clip and aspiration worked well to reduce pan peritonitis. Presently, the ESD technique is the preferred approach in the stomach and esophagus and reasonable to apply this technique to duodenal tumors, even given the thin duodenal wall.

\section{Conclusion}

We reported an experience with a rare case of Fundic Type Gastric Adenocarcinoma, arising from ectopic gastric mucosa, resected by ESD (Endoscopic Submucosal Dissection). 


\section{Acknowledgment}

The authors would like to express their deepest appreciation to Associate Professor Michael K. Gibson MD PhD FACP Case Western Reserve University, for guiding constructive comments, and warm encouragement.

\section{References}

1. Ueyama H, Yao T, Nakashima Y, Hirakawa K, Oshiro Y, et al. (2010) Gastric adenocarcinoma of fundic gland type (chief cell predominant type): proposal for a new entity of gastric adenocarcinoma. Am J Surg Pathol 34: 609-19

2. Tsukamoto T, Yokoi T, Maruta S, Kitamura M, Yamamoto T, et al. (2007) Gastric adenocarcinoma with chief cell differentiation. Pathol Int 57: 517-22.

3. Fukatsu H, Miyoshi H, Ishiki K, Tamura M, Yao T (2011) Gastric adenocarcinoma of fundic gland type (chief cell predominant type) treated with endoscopic aspiration mucosectomy. Dig Endosc 23: 244-6.

4. Park ES, Kim YE, Park CK, Yao T, Kushima R, et al. (2012) Gastric adenocarcinoma of fundic gland type: report of three cases. Korean J Pathol 46: 287-91.

5. Kokkola A, Louhimo J, Puolakkainen P, Alfthan H, Haglund C, et al. (2005) Helicobacter pylori infection and low serum pepsinogen I level as risk factors for gastric carcinoma. World J Gastroenterol 11: 1032-6.

6. Matsukawa A, Kurano R, Takemoto T, Kagayama M, Ito T (2005) Chief cell hyperplasia with structural and nuclear atypia: a variant of fundic gland polyp. Pathol Res Pract 200: 817-21.

7. Yang GY, Liao J, Cassai ND, Smolka AJ, Sidhu GS (2003) Parietal cell carcinoma of gastric cardia: immunophenotype and ultrastructure. Ultrastruct Pathol 27: 87-94.

8. Cortese AF, Cornell GN (1972) Carcinoma of the duodenum. Cancer 29: 1010-5.

9. Vuilleumier H, Cuttat JF, Blum AL, Chapuis G (1994) Adenocarcinoma of the duodenum. Contribution to the study of a rare pathology. Helv Chir Acta 60: 557-67.

10. Singhi AD, Lazenby AJ, Montgomery EA (2012) Gastric adenocarcinoma with chief cell differentiation: a proposal for reclassification as oxyntic gland polyp/ adenoma. Am J Surg Pathol 36: 1030-5

11. Terada T (2011) Well differentiated adenocarcinoma of the stomach composed of chief cell-like cells and parietal cells (Gastric adenocarcinoma of fundic gland type). Int J Clin Exp Pathol 4: 797-8.

12. Tocchi A, Mazzoni G, Puma F, Miccini M, Cassini D, et al. (2003) Adenocarcinoma of the third and fourth portions of the duodenum: results of surgical treatment. Arch Surg 138: 80-5.

13. Hurtuk MG, Devata S, Brown KM, Oshima K, Aranha GV, et al. (2007) Should all patients with duodenal adenocarcinoma be considered for aggressive surgical resection? Am J Surg 193: 319-24.

14. Abbass R, Rigaux J, Al-Kawas FH (2010) Nonampullary duodenal polyps: characteristics and endoscopic management. Gastrointest Endosc 71: 754-9.

15. Al-Kawas FH (2011) The significance and management of nonampullary duodenal polyps. Gastroenterol Hepatol 7: 329-32.

16. Basford PJ, Bhandari P (2012) Endoscopic management of nonampullary duodenal polyps. Therap Adv Gastroenterol 5: 127-38.

17. Perez A, Saltzman JR, Carr-Locke DL, Brooks DC, Osteen RT, et al. (2003) Benign nonampullary duodenal neoplasms. J Gastrointest Surg 7: 536-41.

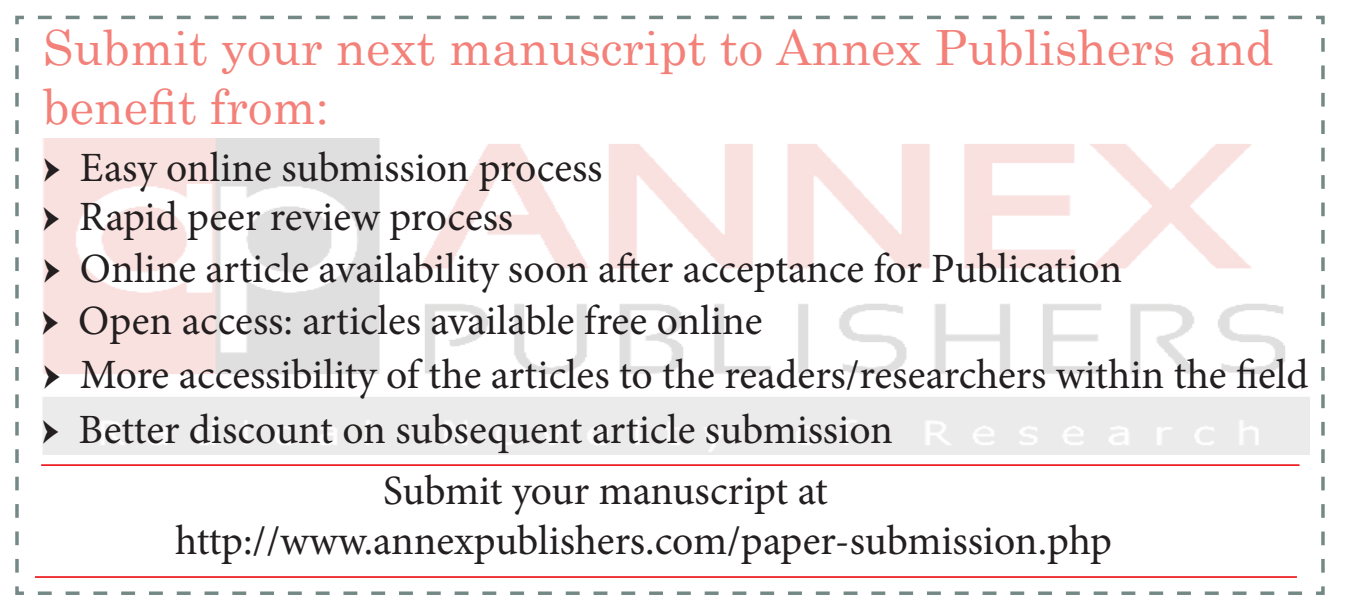

